Article

\title{
A Gate Driver Based on Variable Voltage and Resistance for Suppressing Overcurrent and Overvoltage of SiC MOSFETs
}

\author{
Jiangui Chen ${ }^{1, *}$, Yan $\mathrm{Li}^{1, *}$ and Mei Liang ${ }^{2}$ \\ 1 School of Electrical Engineering, Beijing Jiaotong University, Haidian, Beijing 100044, China \\ 2 Cooperate research Center, ABB China Ltd., Haidian, Beijing 100055, China; mei-mei.liang@cn.abb.com \\ * Correspondence: 17121415@bjtu.edu.cn (J.C.); liyan@bjtu.edu.cn (Y.L.)
}

Received: 15 March 2019; Accepted: 27 April 2019; Published: 29 April 2019

check for updates

\begin{abstract}
A SiC MOSFET is a suitable replacement for a Si MOSFET due to its lower on-state resistance, faster switching speed, and higher breakdown voltage. However, due to the parasitic parameters and the low damping in the circuit, the turn-on overcurrent and turn-off overvoltage of a SiC MOSFET become more severe as the switching speed increases. These effects limit higher frequency applications of SiC MOSFET. Based on the causes of overcurrent and overvoltage of SiC MOSFET, a novel gate driver with the variable driving voltage and variable gate resistance is proposed in this paper to suppress the overcurrent and overvoltage of SiC MOSFETs. The proposed gate driver can realize the variation in driving voltage and gate resistance during switching transitions. It not only suppresses the overcurrent and overvoltage of SiC MOSFETs, but also has little effect on switching loss. The working principle of the proposed gate driver is analyzed in this paper. Finally, experimental verification on a double-pulse test platform is performed to verify the effectiveness of the proposed gate driver.
\end{abstract}

Keywords: SiC MOSFET; overvoltage; overcurrent; switching loss; gate driver

\section{Introduction}

Silicon carbide ( $\mathrm{SiC})$ MOSFETs have the advantages of high breakdown electric field, fast drift saturation of carriers, good thermal stability, and high thermal conductivity [1-5]. These advantages of SiC MOSFETs can improve the performance of electronic converters. The switching frequency of power electronic converters based on $\mathrm{SiC}$ MOSFETs can even reach $\mathrm{MHz}$, and the power density has been greatly improved because of the good switching characteristics of SiC MOSFETs [6-9]. However, the turn-on overcurrent and turn-off overvoltage of SiC MOSFETs become more severe as the switching speed increases due to the parasitic parameters and the low damping in the circuit, which limits the switching frequency of SiC MOSFETs and even damages the devices [7-14]. Therefore, it is necessary to reduce the turn-on overcurrent and turn-off overvoltage of SiC MOSFETs. At present, there are three methods to reduce the turn-on overcurrent and turn-off overvoltage of SiC MOSFETs. The first method is adding an RCD snubber circuit in the switching device or the main power loop $[15,16]$. This method of increasing an RCD snubber circuit can suppress the turn-off overvoltage effectively, but the energy stored in the external capacitor will be released through the device channel when the device is turned on, which could increase the turn-on overcurrent and turn-on loss. The second method is the use of a DC-side snubber, this method can decouple a portion of parasitic inductance from the power loop by paralleling a decoupling capacitor in the bridge circuit. However, the parasitic inductance will resonate with the high-frequency decoupling capacitor if the decoupling capacitor is not large enough. The suppression effect is not good when the high-frequency decoupling capacitor is large enough to 
avoid low-frequency oscillation [14]. The third method to suppress the overvoltage and overcurrent is increasing the gate resistor for slowing the switching speed, but switching loss is greatly increased as a result $[1,17,18]$. Therefore, a two-stage gate driver based on a variable resistor is proposed in the literature [19]. However, a two-stage gate driver only based on a variable resistor cannot achieve lower switching loss. Additionally, a multilevel gate driver based on a switched voltage is proposed [20]; its principle is based on a monotonic gate voltage. The multilevel gate driver can suppress the overvoltage and overcurrent, but the switching loss increases greatly.

A novel gate driving circuit based on variable driving voltage and variable gate resistance topology is proposed in this paper to suppress the overvoltage and overcurrent of $\mathrm{SiC}$. The proposed gate driver can not only suppress the overvoltage and overcurrent of SiC MOSFETs, but also reduce the switching loss when compared with gate drivers presented in the literature. The causes of overvoltage and overcurrent of SiC MOSFETs are analyzed in detail in Section 2. Section 3 provides the topology and operation principle of the proposed gate driver. A double-pulse test platform based on the proposed gate driver is set up in Section 4 to verify the correctness and effectiveness of the proposed gate driver.

\section{Overvoltage and Overcurrent of SiC MOSFETs}

Figure 1 shows a double-pulse circuit considering the parasitic parameters. The circuit shown in Figure 1 can also be used to analyze the switching characteristics of Buck, Boost, Buck-Boost, Half Bridge, and Full Bridge circuits. In Figure 1, the input voltage $V_{\mathrm{DC}}$ and the output current $I_{\mathrm{O}}$ are constant. $Q_{1}$ is a SiC MOSFET. The parasitic parameters are the gate-source junction capacitance $C_{\mathrm{GS}}$, gate-drain junction capacitance $C_{\mathrm{GD}}$, drain-source junction capacitance $C_{\mathrm{DS}}$, gate parasitic inductance $L_{\mathrm{G}}$, common-source parasitic inductance $L_{\mathrm{CS}}$ and internal gate resistance $R_{\mathrm{G} 1} . R_{\mathrm{G} 2}$ is the external gate resistor and $v_{\mathrm{P}}$ is the driving signal of $Q_{1}$.

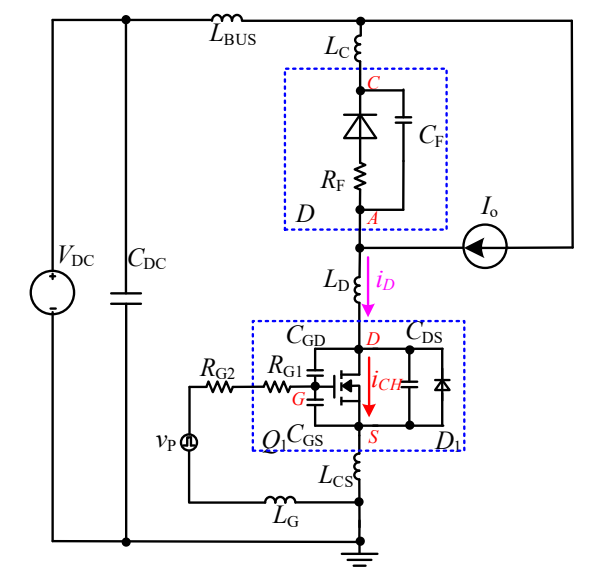

Figure 1. Double-pulse circuit considering the parasitic elements.

The freewheeling diode $D$ uses a $\mathrm{SiC}$ JBS diode. The parasitic parameters inside the package are: junction capacitance $C_{\mathrm{F}}$ and its on-resistance $R_{\mathrm{F}} . L_{\mathrm{C}}, L_{\mathrm{D}}, L_{\mathrm{G}}$, and $L_{\mathrm{BUS}}$ represent the parasitic inductance of the branches where they are located (including parasitic inductances on the package and PCB connection lines).

Figure 2 shows the switching waveforms of $Q_{1}$ : the gate-source voltage $v_{\mathrm{GS}}$, the drain current $i_{\mathrm{D}}$, the drain-source voltage $v_{\mathrm{DS}}$, and the switching waveform of freewheeling diode voltage $v_{\mathrm{F}}$. The switching waveforms of a switching cycle can be divided into ten stages. The turn-on transient includes: Stage 1 (turn-on delay stage), Stage 2 (current-rising stage), Stage 3 (turn-on overcurrent stage), and Stage 4 (current-oscillating stage). The turn-off transient includes: Stage 6 (turn-off delay stage), Stage 7 (voltage-rising stage), Stage 8 (turn-off overvoltage stage), and Stage 9 (voltage-oscillating stage). Stage 5 and Stage 10 are the stable stages after the switching transient. Since this paper mainly analyzes the 
causes of the overcurrent and overvoltage of SiC MOSFETs, the section only analyzes Stage 3, Stage 4, Stage 8, and Stage 9 in detail.

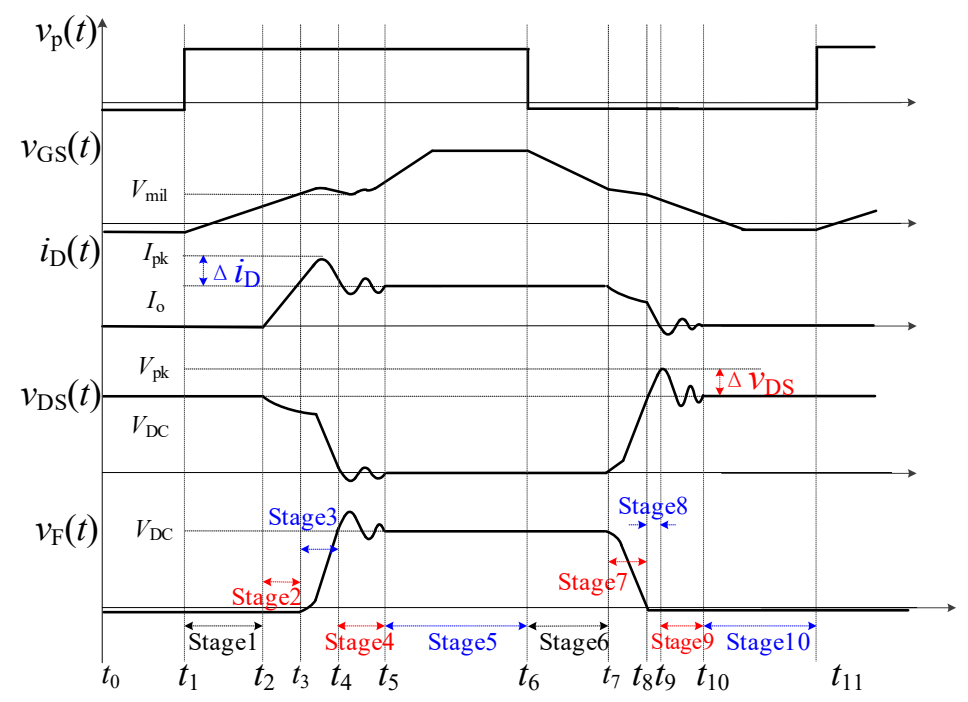

Figure 2. Switching waveforms of a SiC MOSFET and a freewheeling diode.

\subsection{Causes of Turn-On Overcurrent}

Stage 3, Turn-on overcurrent stage. When the $i_{\mathrm{D}}$ of the SiC MOSFET is equal to $I_{0}$, the freewheeling diode $D$ is able to block the voltage. The junction capacitance $C_{F}$ is charged, and the charging current flows through $Q_{1}$ and causes $i_{\mathrm{D}}$ to have an overcurrent. Meanwhile, the junction capacitances $C_{\mathrm{GS}}$ and $C_{\mathrm{DS}}$ of the $\mathrm{SiC}$ MOSFET are discharged, the discharge current flows through its channel, and the channel current $i_{\mathrm{CH}}$ also appears overcurrent. The equivalent circuit at this stage is shown in Figure 3a. The junction capacitance $C_{\mathrm{F}}, C_{\mathrm{GS}}$, and $C_{\mathrm{DS}}$ are equivalent to current sources, and the $Q_{1}$ channel is equivalent to a controlled current source.

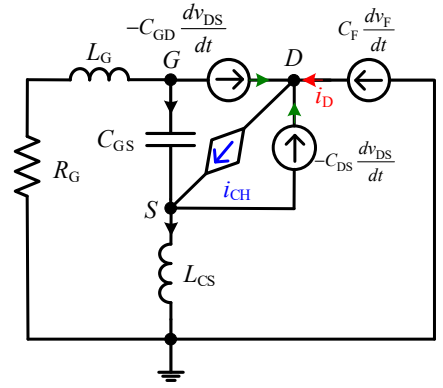

(a)

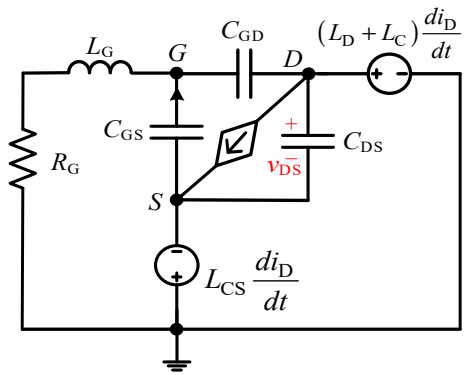

(c)

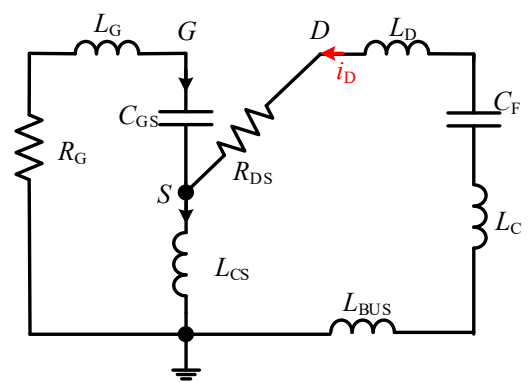

(b)

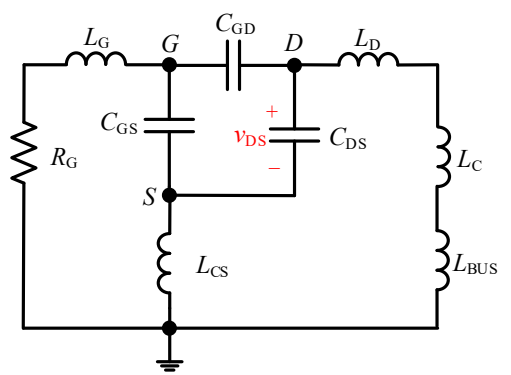

(d)

Figure 3. Equivalent circuit of (a) Stage 3, (b) Stage 4, (c) Stage 8, (d) Stage 9. 
The overcurrent of $i_{\mathrm{D}}$ is shown in Equation (1), and the overcurrent of $i_{\mathrm{CH}}$ is shown in Equation (2).

$$
\begin{gathered}
\Delta i_{\mathrm{D}}=C_{\mathrm{F}} \frac{d v_{\mathrm{F}}}{d t} \\
\Delta i_{\mathrm{CH}}=C_{\mathrm{F}} \frac{d v_{\mathrm{F}}}{d t}-C_{\mathrm{GD}} \frac{d v_{\mathrm{DS}}}{d t}-C_{\mathrm{DS}} \frac{d v_{\mathrm{DS}}}{d t}
\end{gathered}
$$

In the above Equation, $d v_{\mathrm{F}} / d t$ is the voltage variation rate of $v_{\mathrm{F}}$, and $d v_{\mathrm{DS}} / d t$ is the voltage variation rate of $d v_{\mathrm{DS}}$. According to Equation (1) and Equation (2), the overcurrent of $Q_{1}$ is mainly determined by $d v_{\mathrm{F}} / d t$ and $d v_{\mathrm{DS}} / d t$, and the relationship shown in Equation (3) exists at this stage.

$$
\frac{d v_{\mathrm{F}}}{d t} \approx-\frac{d v_{\mathrm{DS}}}{d t} \approx \frac{V_{\mathrm{GS}}-V_{\mathrm{mil}}}{\left(R_{\mathrm{G} 1}+R_{\mathrm{G} 2}\right) C_{\mathrm{GD}}}
$$

In Equation (3), $V_{\text {mil }}$ is the Miller voltage of $Q_{1}$. Since the voltage $V_{\mathrm{GS}}$ changes slightly at this stage, it can be considered as a constant. The turn-on overcurrent can be reduced by reducing the turn-on driving voltage $V_{\mathrm{GS}}$ and increasing the external gate resistance $R_{\mathrm{G} 2}$ according to Equation (3).

Stage 4, Current-oscillating stage. After the diode voltage $v_{\mathrm{F}}$ reaches the input voltage $V_{\mathrm{DC}}$, the $\mathrm{SiC}$ MOSFET can be equivalent to the on-state resistance $R_{\mathrm{DS}}$. The junction capacitance $C_{\mathrm{F}}$ oscillates with the parasitic inductance of the power loop $L_{\mathrm{BUS}}$ to consume the energy stored in $C_{\mathrm{GS}}, C_{\mathrm{DS}}, C_{\mathrm{F}}$ before time $t_{2}$. The equivalent circuit at this stage is shown in Figure $3 \mathrm{~b}$.

\subsection{Causes of Turn-Off Overvoltage}

Stage 8, Turn-off overvoltage stage. After the drain-source voltage $v_{\mathrm{DS}}$ is equal to $V_{\mathrm{DC}}, D$ turns on. $\mathrm{Q} 1$ and $D$ commutate, the rapid $d i_{\mathrm{D}} / d t$ creates a voltage drop in the parasitic inductance $L_{\mathrm{P}}$. The voltage drop is superimposed on the drain-source of $Q_{1}$ and a turn-off overvoltage appears. The equivalent circuit of this stage is shown in Figure 3c, and the overvoltage can be calculated by Equation (4). At this stage, $i_{\mathrm{D}}$ is approximately equal to $i_{\mathrm{CH}}$. Equation (5) can be derived according to the transconductance relationship of the SiC MOSFET.

$$
\begin{gathered}
\Delta v_{\mathrm{DS}}=L_{\mathrm{P}} \frac{d i_{\mathrm{D}}}{d t} \\
\frac{d i_{\mathrm{D}}}{d t} \approx \frac{d \mathrm{i}_{\mathrm{CH}}}{d t}=g_{f} \frac{d v_{\mathrm{GS}}}{d t}
\end{gathered}
$$

where $L_{\mathrm{P}}=L_{\mathrm{BUS}} L_{\mathrm{C}}+L_{\mathrm{D}}+L_{\mathrm{CS}}$, and $g_{f}$ is the transconductance of $Q_{1}$.

Stage 9 , Voltage-oscillating stage. When the $i_{\mathrm{D}}$ drops to 0 , the channel of the $Q_{1}$ is turned off. The $C_{\mathrm{GD}}$ and $C_{\mathrm{DS}}$ oscillate with the parasitic inductance $L_{\mathrm{P}}$ to consume the energy stored in $L_{\mathrm{P}}$ before time $t_{8}$. The equivalent circuit in this stage is shown in Figure 3d.

Based on the above analysis, the parasitic inductance $L_{\mathrm{P}}$, transconductance $g_{f}$, and $d v_{\mathrm{GS}} / d t$ can determine the turn-off overvoltage. $g_{f}$ is a device parameter and it is not easy to change. Reducing the turn-off driving voltage amplitude $-V_{\mathrm{SS}}$ and increasing the external gate resistance $R_{\mathrm{G}}$ at this stage can suppress the turn-off overvoltage.

\section{Proposed Gate Driving Circuit}

Based on the analysis in Section 2, the turn-on overcurrent and turn-off overvoltage can be suppressed by reducing the driving voltage amplitude $v_{\mathrm{P}}$ and increasing the external gate resistance $R_{\mathrm{G}}$. However, when this method is applied to the entire switching cycle, it will slow down switching speed in each stage. The switching loss will increase as a result.

Therefore, a novel gate driver based on the variable driving voltage and variable gate resistance topology for SiC MOSFETs is proposed in this paper. This proposed gate driver adopts different driving voltage and gate resistance during different switching stages. It can not only suppress the turn-on overcurrent and turn-off overvoltage but can also avoid serious switching loss. 


\subsection{Parameters Design of the Proposed Gate Driver}

Figure 4 shows the structure of the proposed drive circuit. $S_{1}-S_{4}$ are used to control the level of the driving voltage, and $S_{\mathrm{A} 1}$ and $S_{\mathrm{A} 2}$ are used to control the values of the gate resistance. $R_{\mathrm{G} 3}$ and $R_{\mathrm{G} 4}$ are smaller gate resistors, and $R_{\mathrm{G} 5}$ and $R_{\mathrm{G} 6}$ are larger gate resistors. The waveforms of the signals $S_{1}-S_{4}$ and $S_{\mathrm{A} 1}-S_{\mathrm{A} 2}$, gate-source voltage $v_{\mathrm{GS}}$, drain current $i_{\mathrm{D}}$, drain-source voltage $v_{\mathrm{DS}}$, and freewheeling diode $D$ voltage $v_{\mathrm{F}}$ of the novel drive circuit are shown in Figure 5.

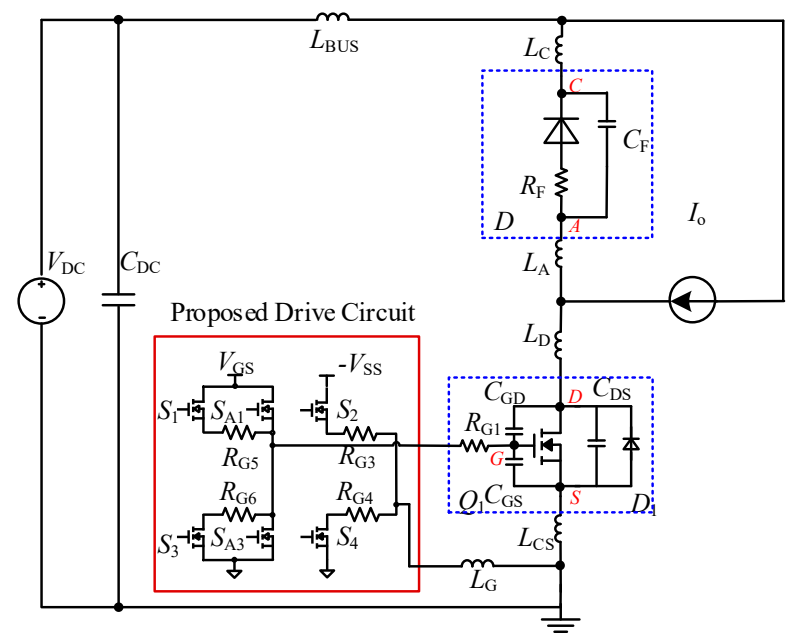

Figure 4. Double-pulse circuit based on the proposed gate driver.

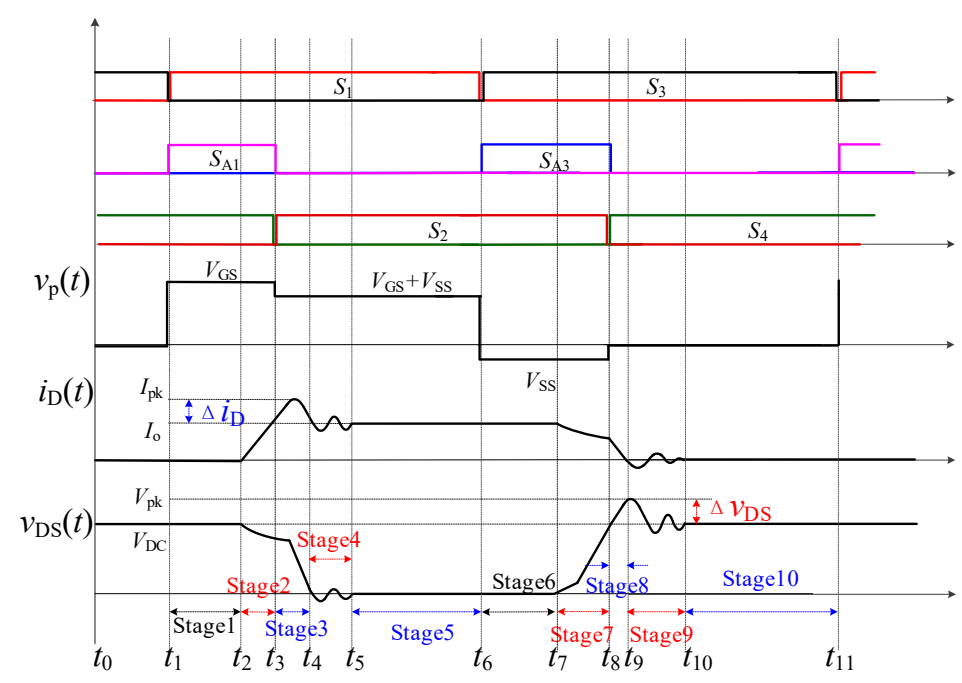

Figure 5. Switching waveforms based on the proposed gate driver.

In order to suppress the overcurrent and overvoltage of SiC MOSFETs and avoid a serious increase in switching loss at the same time, the proposed gate driver needs to meet the following requirements:

1) Turn-on delay and current-rising stages. In order to achieve a faster turn-on speed to reduce turn-on loss during these two stages, the gate resistance should be set as small as possible and the driving voltage during the two stages should be higher than normal, but the driving voltage cannot exceed the gate-source positive safety voltage (25V) of SiC MOSFET.

2) Turn-on overcurrent and current-oscillating stages. In order to reduce the $d v_{\mathrm{DS}} / d t$, a larger gate resistance should be adopted during these two stages. The driving voltage of the SiC MOSFET should be reduced, but it cannot be lower than the recommended driving voltage $(18 \mathrm{~V})$.

3) Turn-off delay and voltage-rising stages. When compared with the traditional gate driver with $0 \mathrm{~V}$ turn-off voltage, the turn-off speed is faster when the turn-off voltage is negative. In order to achieve a 
faster turn-off speed to reduce turn-off loss during these two stags, the turn-off voltage can be set to a negative voltage $(<0 \mathrm{~V},>-10 \mathrm{~V})$, and a small gate resistance should be set.

4) Turn-off overvoltage and voltage-oscillating stages. In order to reduce $d i_{\mathrm{D}} / d t$, the turn-off driving voltage no longer uses a negative voltage and a larger gate resistance should be set.

\subsection{Working Principle of the Proposed Gate Driving Circuit}

The working modes of the proposed driving circuit are as follows. Table 1 shows the driving voltage and gate resistor in each mode of the proposed driving circuit.

Table 1. Driving voltage and gate resistor in each mode.

\begin{tabular}{cccc}
\hline Working Modes & Switching Stages & Driving Voltage & Gate Resistance \\
\hline Mode 1 & Stages 1-2 $\left[t_{1}-t_{3}\right]$ & $V_{\mathrm{GS}}$ & $R_{\mathrm{G} 1}+R_{\mathrm{G} 4}$ \\
Mode 2 & Stages 3-5 $\left[t_{3}-t_{6}\right]$ & $V_{\mathrm{GS}}+V_{\mathrm{SS}}$ & $R_{\mathrm{G} 1}+R_{\mathrm{G} 3}+R_{\mathrm{G} 5}$ \\
Mode 3 & Stages 6-7 $\left[t_{6}-t_{8}\right]$ & $V_{\mathrm{SS}}$ & $R_{\mathrm{G} 1}+R_{\mathrm{G} 3}$ \\
Mode 4 & Stages $8-10\left[t_{8}-t_{11}\right]$ & $0 \mathrm{~V}$ & $R_{\mathrm{G} 1}+R_{\mathrm{G} 4}+R_{\mathrm{G} 6}$ \\
\hline
\end{tabular}

We assume that the driving circuit is in a stable state before time $t_{1}, S_{3}$ and $S_{4}$ are in the on-state, the gate resistance is $R_{\mathrm{G} 1}+R_{\mathrm{G} 4}+R_{\mathrm{G} 6}, Q_{1}$ is in the off-state, and the freewheeling diode $D$ freewheels.

Mode 1: At time $t_{1}, S_{1}, S_{4}$, and $S_{\mathrm{A} 1}$ are turned on and $S_{3}$ is turned off. The driving signal $v_{\mathrm{P}}$ of $Q_{1}$ changes from $0 \mathrm{~V}$ to $V_{\mathrm{GS}}$, and the gate resistance becomes $R_{\mathrm{G} 1}+R_{\mathrm{G} 4}$. The smaller the $R_{\mathrm{G} 4}$, the faster the speed of these two stages. Therefore, $R_{\mathrm{G} 4}$ can choose a $10 \Omega$ resistor. At time $t_{3}, i_{\mathrm{D}}$, rises to $I_{\mathrm{O}}$, freewheeling diode $D$ turns off, and this mode ends. The equivalent circuit of this mode is shown in Figure 6a. In this mode, the turn-on delay time and current-rise time of the $Q_{1}$ are shortened.

Mode 2: At time $t_{3}, S_{1}$ and $S_{2}$ are turned on, $S_{4}$ and $S_{\mathrm{A} 1}$ are turned off; the driving signal $v_{\mathrm{P}}$ of $Q_{1}$ becomes $V_{\mathrm{GS}}+V_{\mathrm{SS}}$, and the gate resistance becomes $R_{\mathrm{G} 1}+R_{\mathrm{G} 3}+R_{\mathrm{G} 5}$. During these two stages, $V_{\mathrm{GS}}+V_{\mathrm{SS}}$ depends on $V_{\mathrm{GS}}$ and $V_{\mathrm{SS}}$ and cannot be changed. The larger the $R_{\mathrm{G} 5}$, the lower the turn-on overcurrent of $Q_{1}$. However, the turn-off process does not end completely, and the turn-off loss will increase as $R_{\mathrm{G} 5}$ increases. Therefore, the value of $R_{\mathrm{G} 5}$ should be a tradeoff between the turn-on overcurrent and turn-on loss. At time $t_{6}$, the turn-off signal of $Q_{1}$ arrives and this mode ends. The equivalent circuit is shown in Figure 6b. In this mode, the turn-on overcurrent and oscillation of $Q_{1}$ are suppressed.

Mode 3: $S_{2}, S_{3}$, and $S_{\mathrm{A} 3}$ are turned on and $S_{1}$ is turned off at time $t_{6}$. The driving signal $v_{\mathrm{P}}$ of $Q_{1}$ changes from $0 \mathrm{~V}$ to $V_{\mathrm{SS}}$, and the gate resistance becomes $R_{\mathrm{G} 1}+R_{\mathrm{G} 3}$. The smaller the $R_{\mathrm{G} 3}$, the faster the speed of these two stages, and a $10 \Omega$ resistor can be chosen as $R_{\mathrm{G} 3}$. At time $t_{8}, v_{\mathrm{DS}}$ rises to $V_{\mathrm{DC}}$, freewheeling diode $D$ conducts, and this mode ends. The equivalent circuit of this mode is shown in Figure 6c. In this mode, the turn-off delay time and voltage-rising time of the $Q_{1}$ are shortened, and the turn-off loss decreases as a result.

Mode 4: At time $t_{6}, S_{3}$ and $S_{4}$ are turned on, and $S_{2}$ and $S_{\mathrm{A} 3}$ are turned off. The driving signal $v_{\mathrm{P}}$ of $Q_{1}$ becomes $0 \mathrm{~V}$, and the gate resistance becomes $R_{\mathrm{G} 1}+R_{\mathrm{G} 4}+R_{\mathrm{G} 6}$. The larger the $R_{\mathrm{G} 6}$, the lower the turn-off overvoltage of $Q_{1}$. However, the turn-off process does not end completely, the turn-off loss will increase as $R_{\mathrm{G} 6}$ increases. Therefore, the value of $R_{\mathrm{G} 6}$ should be a tradeoff between the turn-off overvoltage and turn-off loss. At $t_{9}$, the turn-on signal of $Q_{1}$ arrives and this mode ends. This mode equivalent circuit is shown in Figure 6d. In this mode, the turn-off overvoltage and oscillation of $Q_{1}$ are suppressed. 


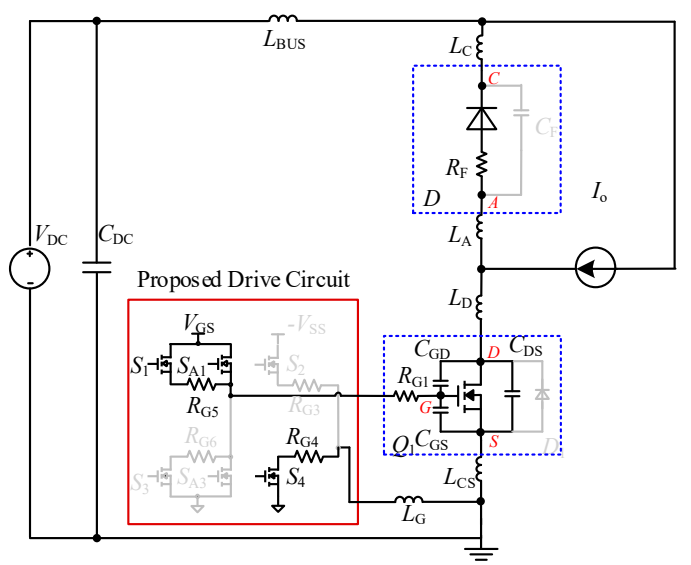

(a)

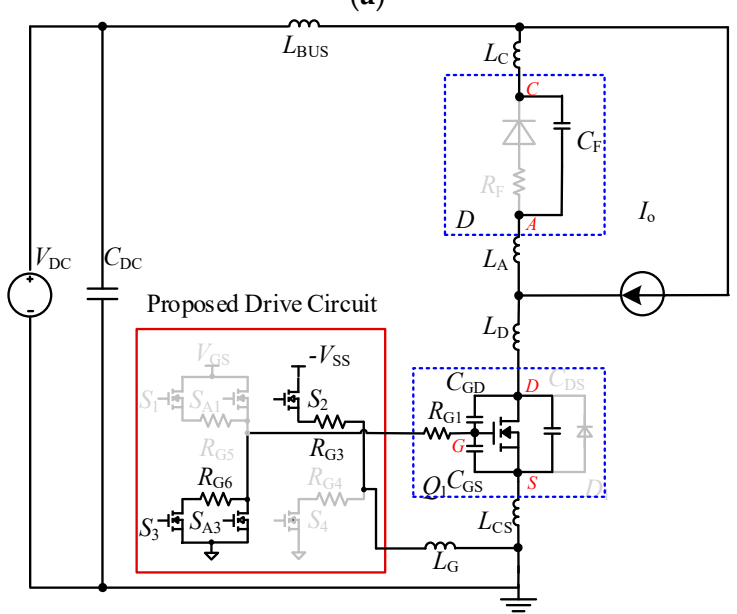

(c)

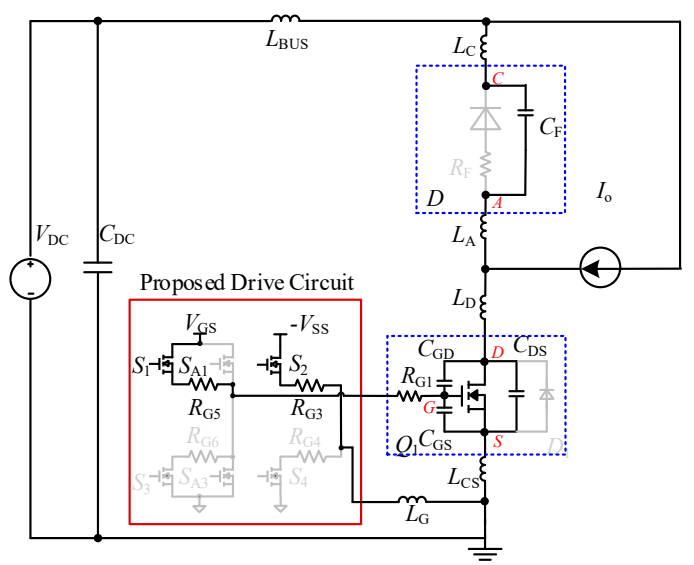

(b)

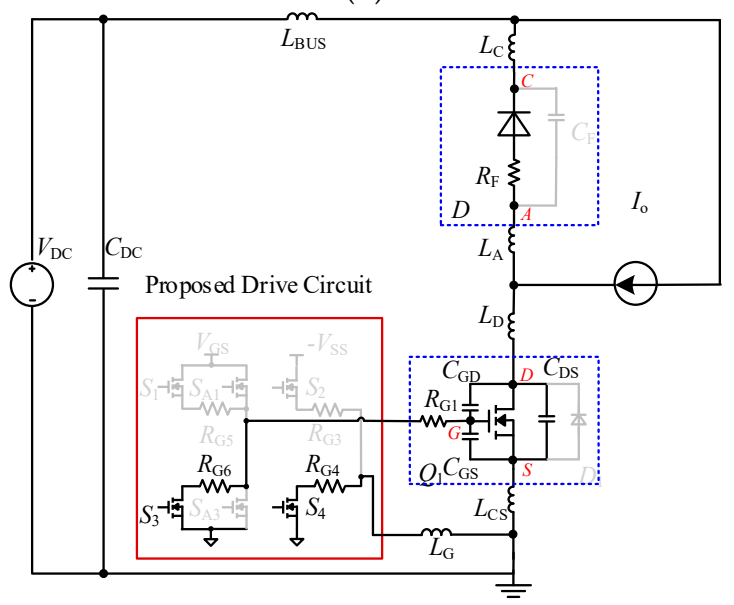

(d)

Figure 6. Equivalent circuit of each working mode: (a) Mode 1, (b) Mode 2, (c) Mode 3, and (d) Mode 4.

\section{Experimental Verification}

In order to verify the advantages of the gate driving circuit proposed in this paper, a double-pulse test platform based on the proposed gate driver was built.

\subsection{Design of the Double-Pulse Test Platform}

Figure 7 shows the double-pulse test platform based on the proposed gate driver. The doublepulse test platform is composed of a double-pulse circuit, a digital controller and the proposed gate driver. In the double-pulse circuit, the SiC MOSFET and diode are C2M0080120D and C4D20120A produced by Cree. Coaxial shunt produced by T \& M Researcher is adopted to ensure the accuracy of current measurement. 


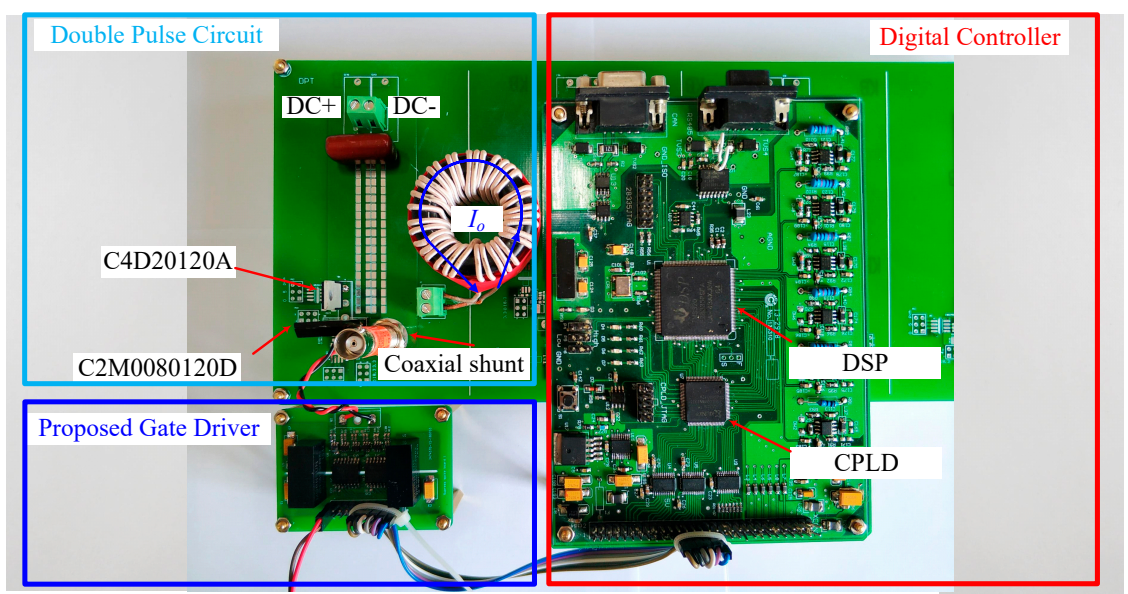

Figure 7. Double-pulse test platform based on the proposed gate driver.

Considering that the maximum turn-on driving voltage of the SiC MOSFET is $25 \mathrm{~V}$ and the maximum turn-off driving voltage is $-10 \mathrm{~V}$, the recommended driving voltage is $20 \mathrm{~V}$ to $-5 \mathrm{~V}$. Therefore, the proposed drive circuit has a $V_{\mathrm{GS}}$ of $24 \mathrm{~V}$ and a $V_{\mathrm{SS}}$ of $-5 \mathrm{~V}$. This not only meets the requirements of the proposed driver, but also ensures that the on-state resistance of the SiC MOSFET is small during the conducting stage. In the driving loop, gate parasitic inductance $L_{G}$, common-source parasitic inductance $L_{\mathrm{CS}}$, gate-source junction capacitance $C_{\mathrm{GS}}$ and external gate resistance $R_{\mathrm{G}}$ form an LCR resonant circuit, as shown in Figure 8. The overvoltage and oscillation may occur in the gate-source voltage $v_{\mathrm{GS}}$. The gate-source voltage $v_{\mathrm{GS}}$ can be calculated according to the Equation (6).

$$
\left(L_{\mathrm{G}}+L_{\mathrm{CS}}\right) C_{\mathrm{GS}} \frac{\mathrm{d}^{2} v_{\mathrm{GS}}}{\mathrm{d}^{2} t}+R_{\mathrm{G}} C_{\mathrm{GS}} \frac{d v_{\mathrm{GS}}}{d t}+v_{\mathrm{GS}}=V_{\mathrm{G}}
$$

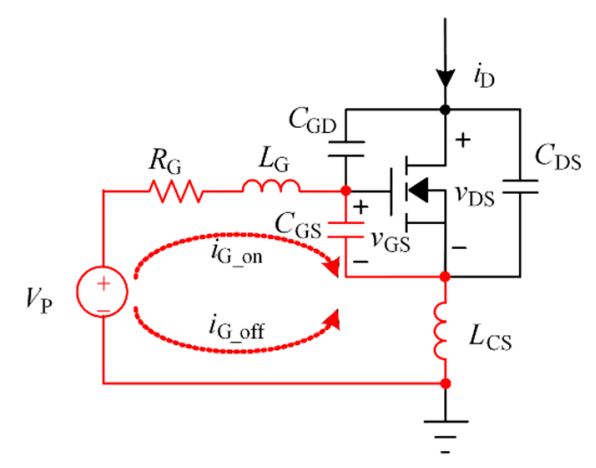

Figure 8. Gate drive considering parasitic parameters.

In order to avoid gate-source voltage oscillation, the external gate resistance $R_{\mathrm{G}}$ needs to satisfy inequality (7). The sum of $L_{\mathrm{CS}}$ and $L_{\mathrm{G}}$ of the double-pulse circuit is approximately $25 \mathrm{nH}, C_{\mathrm{GS}}$ of a C2M0080120D is about $1.2 \mathrm{nF}$. Therefore, $10 \Omega$ resistor is selected for $R_{\mathrm{G} 3}$ and $R_{\mathrm{G} 4}$

$$
R_{\mathrm{G}} \geq 2 \sqrt{\frac{L_{\mathrm{G}}+L_{\mathrm{CS}}}{C_{\mathrm{GS}}}}
$$

In the proposed gate driver, a larger resistor should be selected for $R_{\mathrm{G} 5}$ and $R_{\mathrm{G} 6}$ to reduce the overshoot of the SiC MOSFET in Stage 3 and Stage 8. However, the larger $R_{\mathrm{G} 5}$ and $R_{\mathrm{G} 6}$ are, the larger the switching loss is. Therefore, it is necessary to balance the overshoot and turn-on loss to select $R_{\mathrm{G} 5}$ and $R_{\mathrm{G} 6}$, a $50 \Omega$ resistor are selected for $R_{\mathrm{G} 5}$ and $R_{\mathrm{G} 6}$. The driving parameters of the proposed gate diver are shown in Table 2. 
Table 2. Driving parameters of the proposed gate diver.

\begin{tabular}{|c|c|c|}
\hline \multicolumn{2}{|c|}{ Name } & \multirow{3}{*}{$\begin{array}{c}\text { Parameters } \\
400 \mathrm{~V} / 500 \mathrm{~V} / 600 \mathrm{~V} \\
11 \mathrm{~A} / 16 \mathrm{~A} / 21 \mathrm{~A}\end{array}$} \\
\hline Main rimarit & Input voltage & \\
\hline Main circuit & Output current & \\
\hline \multirow{6}{*}{ Proposed gate driver } & $V_{\mathrm{GS}}$ & $24 \mathrm{~V}$ \\
\hline & $V_{\mathrm{SS}}$ & $-5 \mathrm{~V}$ \\
\hline & $R_{\mathrm{G} 3}$ & $10 \Omega$ \\
\hline & $R_{\mathrm{G} 4}$ & $50 \Omega$ \\
\hline & $R_{\mathrm{G} 5}$ & $10 \Omega$ \\
\hline & $R_{\mathrm{G} 6}$ & $50 \Omega$ \\
\hline
\end{tabular}

In order to verify the effectiveness of the proposed gate driver, this paper gives the results of a comparative test performed between the proposed gate driver and traditional gate drivers. The traditional gate driver used different driving parameters, as shown in Table 3.

Table 3. Driving parameters of traditional gate drivers.

\begin{tabular}{ccccc}
\hline $\begin{array}{c}\text { Traditional } \\
\text { Gate Drivers }\end{array}$ & \multicolumn{2}{c}{ Turn-On Stages } & \multicolumn{2}{c}{ Turn-Off Stages } \\
\hline & Driving Voltage & Gate Resistance & Driving Voltage & Gate Resistance \\
\hline Driver $^{\mathbf{1}}$ & $24 \mathrm{~V}$ & $10 \Omega$ & $-5 \mathrm{~V}$ & $10 \Omega$ \\
Driver $^{\mathbf{2}}$ & $19 \mathrm{~V}$ & $50 \Omega$ & $0 \mathrm{~V}$ & $50 \Omega$ \\
\hline
\end{tabular}

The PCB of the proposed gate driver is shown in Figure 9. Six nonisolated driver chips (UCC27531) produced by TI were selected as $S_{1}-S_{4}$ and $S_{\mathrm{A} 1}-S_{\mathrm{A} 2}$. Two isolation chips (ISO7230M) produced by TI are used to ensure effective isolation between the control circuit and the main power circuit. $V_{G S}$ and $-V_{\mathrm{SS}}$ are provided by the auxiliary power WRE0512S-3WR2 and WRF0505S-3WR2, respectively. To reduce the space, the SMD resistors of 0603 package are selected as gate resistance. The driving signals for $S_{1}-S_{4}$ and $S_{\mathrm{A} 1}-S_{\mathrm{A} 2}$ are provided by a TMS320F28335 digital signal processor.

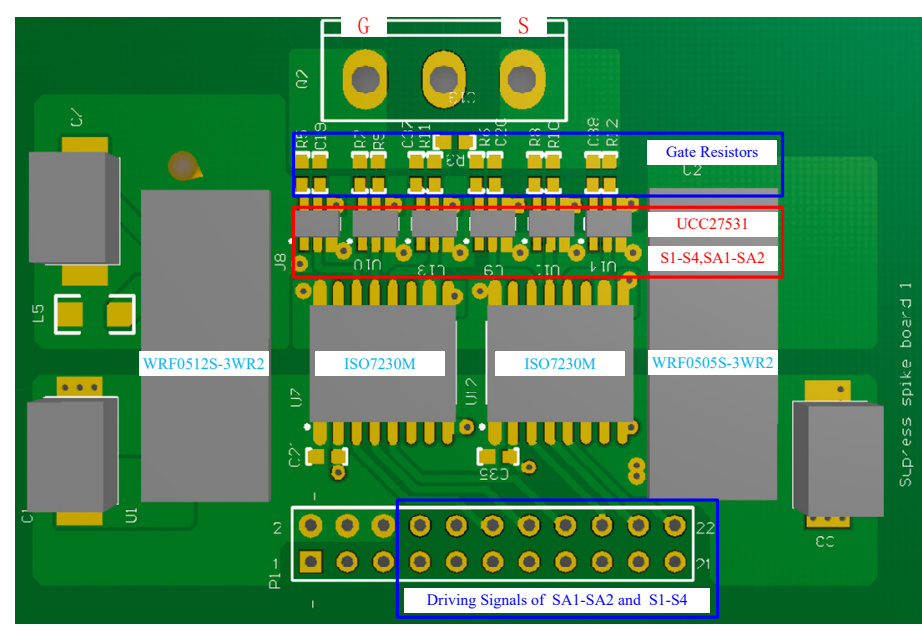

Figure 9. Printed circuit board (PCB) of the proposed gate driver.

When using the proposed gate driver, the time of Stage 1-2 and Stage 6-7 must be solved to determine the switching points in Figure 5. The time of these four stages can be obtained by the LTspice simulation or the datasheet of the SiC MOSFET provided by the manufacturer. However, the double-pulse test is the most accurate method to solve the time. This paper used the double-pulse test to solve the time of these four stages. In order to achieve faster switching speed, the proposed gate driver and traditional gate driver have the same driving parameters during these four stages. 
Therefore, when the double-pulse test adopts the traditional gate driver, the time of these four stages can be easily measured. Table 4 gives the time of the four stages with traditional driver ${ }^{1}$.

Table 4. Time of Stage 1, Stage 2, Stage 3, Stage 4 with traditional driver.

\begin{tabular}{cc}
\hline Switching Stages & Time/ns \\
\hline Stag 1 & 18 \\
Stag 2 & 24 \\
Stag 6 & 24 \\
Stag 7 & 20 \\
\hline
\end{tabular}

Table 5 shows the test equipment used for the double-pulse test platform.

Table 5. Test equipment for the double-pulse test platform.

\begin{tabular}{ccc}
\hline Name & Type & Bandwidth/MHz \\
\hline Oscilloscope & Tektronix DPO4054B & 500 \\
Differential Voltage probe & Tektronix P6139B & 500 \\
Passive Voltage probe & Tektronix P2220 & 200 \\
Coaxial shunt & SSDN-414-025 & 2500 \\
\hline
\end{tabular}

\subsection{Test Results of the Turn-on Process}

The turn-on waveforms of the gate-source voltage $v_{\mathrm{GS}}$, drain current $i_{\mathrm{D}}$, drain-source voltage $v_{\mathrm{DS}}$, and switching loss based on different gate drivers are given in Figure 10, and the experiment was conducted under an input voltage of $600 \mathrm{~V}$ and an output current of $21 \mathrm{~A}$.

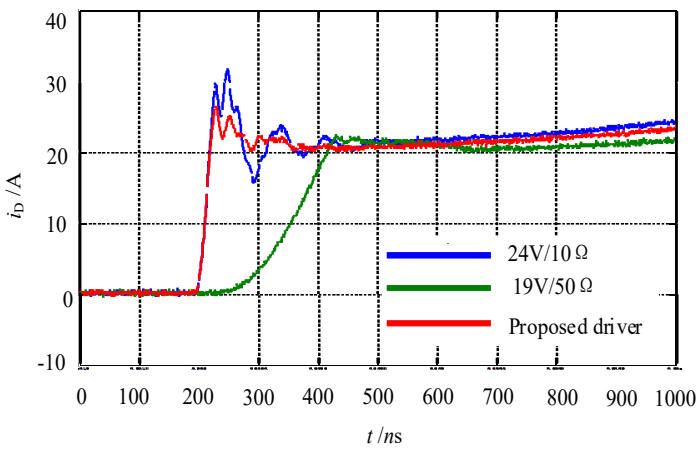

(a)

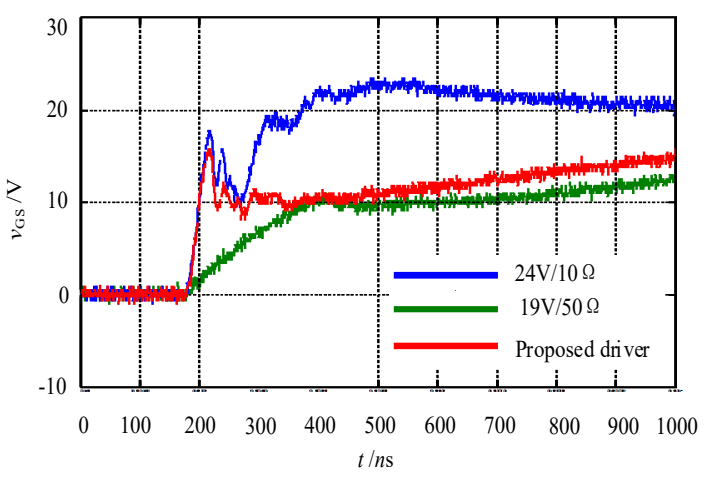

(c)

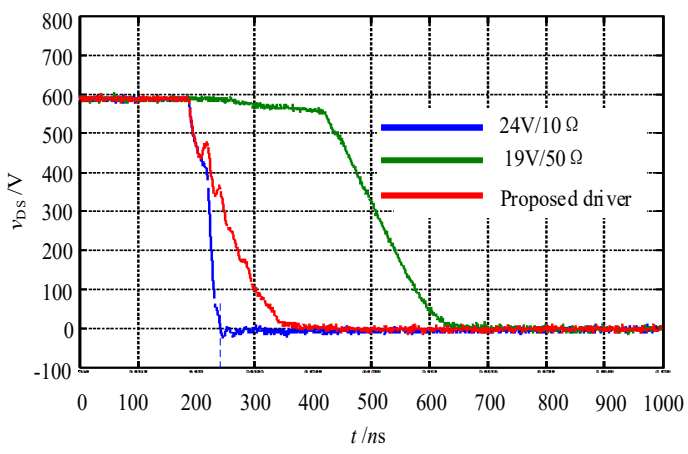

(b)

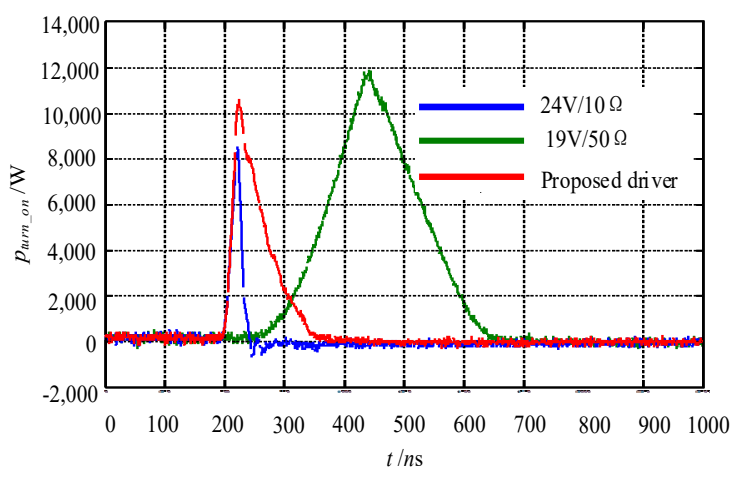

(d)

Figure 10. Switching waveforms based on different gate drivers: (a) Turn-on current waveforms, (b) Turn-on voltage waveforms, (c) Gate driving waveforms, and (d) Turn-on loss waveforms.

The experimental comparison results of the turn-on process are shown in Table 6. 
Table 6. Experimental results of the turn-on process based on different gate drivers.

\begin{tabular}{cccc}
\hline Turn-on Parameters & $\begin{array}{c}\text { Driver }^{\mathbf{1}} \\
(\mathbf{2 4} \mathbf{~ V / 1 0 ~} \mathbf{\Omega})\end{array}$ & $\begin{array}{c}\text { Driver }^{\mathbf{2}} \\
(\mathbf{1 9} \mathbf{V} / \mathbf{5 0} \mathbf{\Omega})\end{array}$ & Proposed Gate Driver \\
\hline Current spike & $32 \mathrm{~A}$ & $22.7 \mathrm{~A}$ & $26.6 \mathrm{~A}$ \\
Delay time & $18 \mathrm{~ns}$ & $60 \mathrm{~ns}$ & $19 \mathrm{~ns}$ \\
Current-rising time & $24 \mathrm{~ns}$ & $164 \mathrm{~ns}$ & $24 \mathrm{~ns}$ \\
Voltage-dropping time & $60 \mathrm{~ns}$ & $350 \mathrm{~ns}$ & $129 \mathrm{~ns}$ \\
Turn-on loss & $0.203 \mathrm{~mJ}$ & $2.031 \mathrm{~mJ}$ & $0.494 \mathrm{~mJ}$ \\
\hline
\end{tabular}

When using a traditional driver with driving parameters of $24 \mathrm{~V} / 10 \Omega$, the SiC MOSFET has the fastest turn-on speed and the lowest turn-on loss but the highest current spike. When using a traditional driver with driving parameters of $19 \mathrm{~V} / 50 \Omega$, the turn-on current spike of the SiC MOSFET is reduced by $9.3 \mathrm{~A}$, but the turn-on loss increases by $1.828 \mathrm{~mJ}$. When using the novel drive circuit, the turn-on current spike is reduced by $5.4 \mathrm{~A}$ and the turn-on loss is only increased by $0.291 \mathrm{~mJ}$.

\subsection{Test Results of the Turn-Off Process}

The turn-off waveforms based on different gate drivers are given in Figure 11.

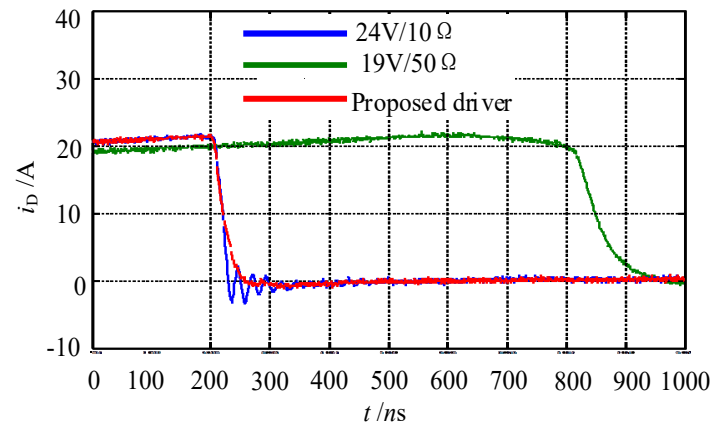

(a)

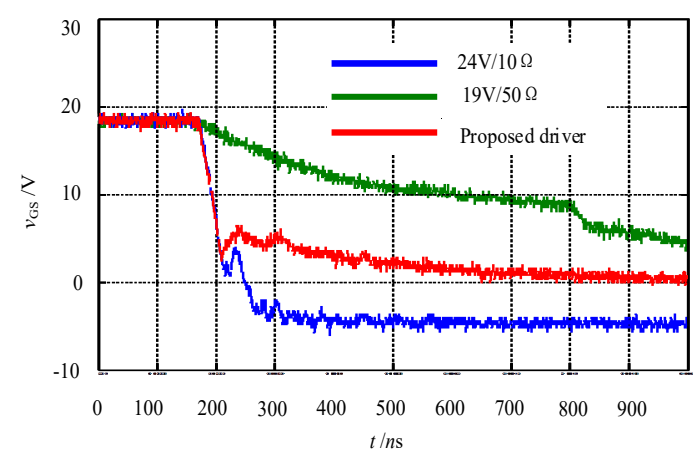

(c)

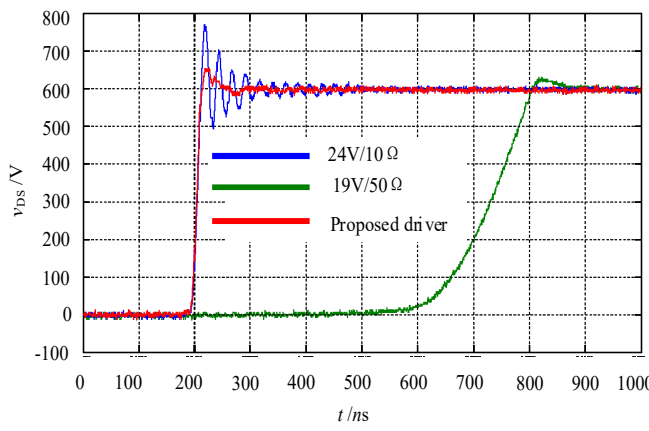

(b)

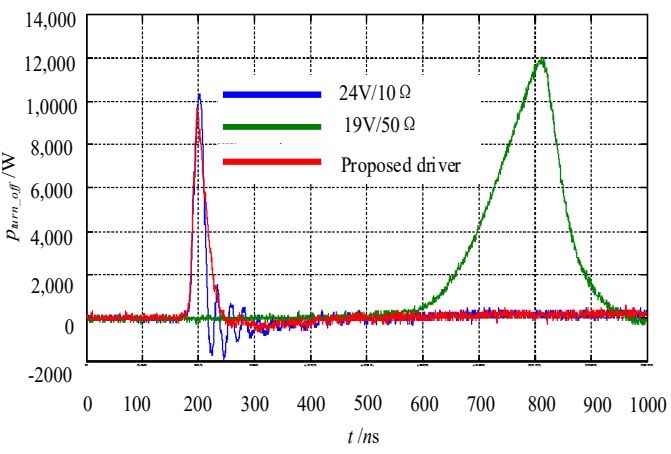

(d)

Figure 11. Switching waveforms based on different gate drivers: (a) Turn-off current waveforms, (b) Turn-off voltage waveforms, (c) Gate driving waveforms, and (d) Turn-off loss waveforms.

The experimental comparison results of the turn-off process are shown in Table 7 . When using traditional driver with the driving parameter of $-5 \mathrm{~V} / 10 \Omega$, the SiC MOSFET has the fastest turn-off speed, the lowest turn-off loss, but the largest voltage spike. The turn-off voltage spike of the SiC MOSFET is reduced by $145 \mathrm{~V}$ when the traditional driver adopts the driving parameter of $0 \mathrm{~V} / 50 \Omega$, but the turn-off loss increases by $1.496 \mathrm{~mJ}$. When using the proposed gate driver, the turn-off voltage spike is reduced by $105 \mathrm{~V}$ and the turn-off loss is only increased by $0.078 \mathrm{~mJ}$. 
Table 7. Experimental results of turn-off process based on different gate drivers.

\begin{tabular}{cccc}
\hline Turn-off Parameters & $\begin{array}{c}\text { Driver }^{\mathbf{1}} \\
(-\mathbf{5 ~ V / 1 0 ~} \mathbf{\Omega})\end{array}$ & $\begin{array}{c}\text { Driver }^{\mathbf{2}} \\
(\mathbf{0 ~ V / 5 0 ~} \mathbf{\Omega})\end{array}$ & Proposed Gate Driver \\
\hline Voltage spike & $765 \mathrm{~V}$ & $620 \mathrm{~V}$ & $660 \mathrm{~V}$ \\
Delay time & $24 \mathrm{~ns}$ & $400 \mathrm{~ns}$ & $25 \mathrm{~ns}$ \\
Voltage-rising time & $20 \mathrm{~ns}$ & $220 \mathrm{~ns}$ & $19 \mathrm{~ns}$ \\
Current-dropping time & $20 \mathrm{~ns}$ & $290 \mathrm{~ns}$ & $45 \mathrm{~ns}$ \\
Turn-off loss & $0.179 \mathrm{~mJ}$ & $1.675 \mathrm{~mJ}$ & $0.257 \mathrm{~mJ}$ \\
\hline
\end{tabular}

\subsection{Test Results under Different Working Conditions}

Figure 12 shows the experimental test results with different gate drivers for respective input voltage and output current of $400 \mathrm{~V} / 11 \mathrm{~A}, 500 \mathrm{~V} / 16 \mathrm{~A}, 600 \mathrm{~V} / 21 \mathrm{~A}$. According to the test results, the traditional gate driver with the driving parameters $24 \mathrm{~V} / 10 \Omega$ and $-5 \mathrm{~V} / 10 \Omega$ has the highest turn-on overcurrent, highest turn-off overvoltage, fastest switching speed, and lowest switching loss. Although the traditional gate driver with driving parameters $19 \mathrm{~V} / 50 \Omega$ and $0 \mathrm{~V} / 50 \Omega$ can suppress the turn-on overcurrent and turn-off overvoltage of the SiC MOSFET, the switching loss increases rapidly.

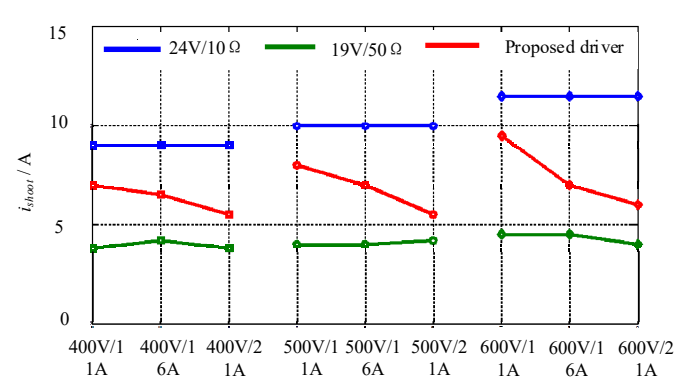

(a)

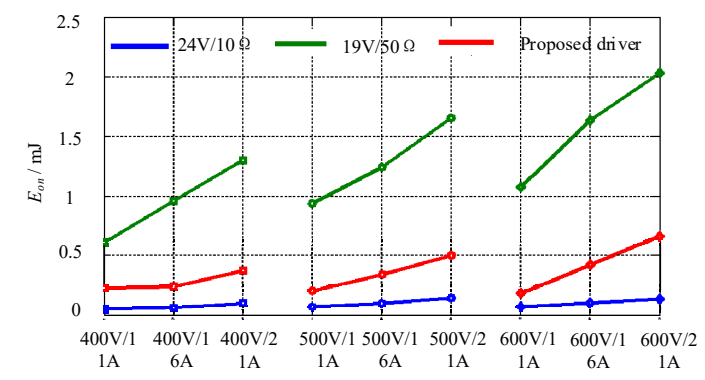

(c)

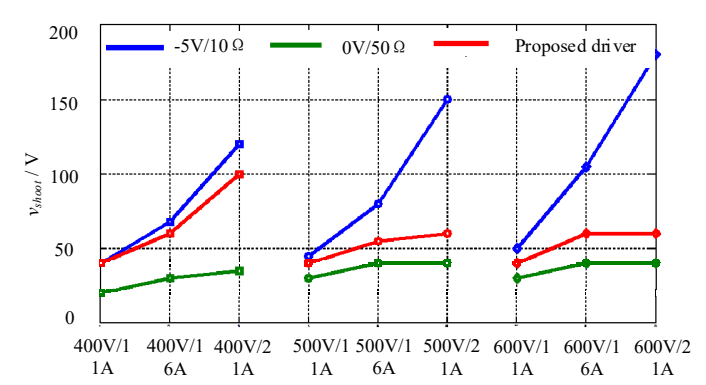

(b)

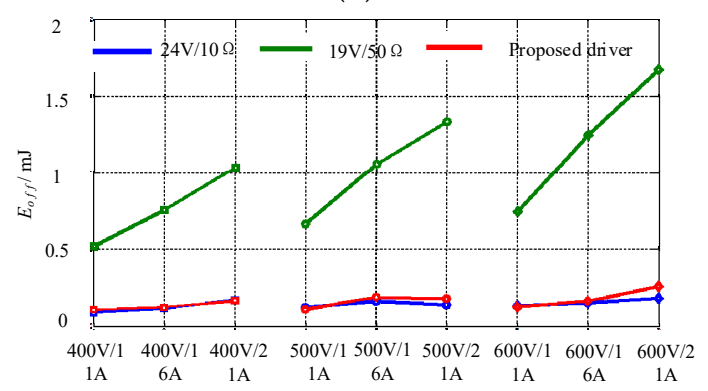

(d)

Figure 12. Experimental results under the different working conditions: (a) Overshoot current, (b) Overshoot voltage, (c) Turn-on loss, and (d) Turn-off loss.

By comparison, the proposed gate driver can suppress the turn-on overcurrent and turn-off overvoltage of the SiC MOSFET effectively and has little effect on switching loss.

\section{Conclusions}

This paper analyzed the causes of the turn-on overshoot current, turn-off overvoltage, and switching oscillation of SiC MOSFETs. The analysis results verified that the turn-on overcurrent and turn-off overvoltage can be suppressed by reducing the amplitude of the driving voltage $v_{\mathrm{P}}$ and increasing the external gate resistance. Based on the theoretical analysis, this paper proposed a novel gate driver based on the variable driving voltage and variable gate resistance topology for $\mathrm{SiC}$ MOSFETs. The proposed gate driver was tested under different working conditions to verify its suppression effect on the turn-on overcurrent and turn-off overvoltage of SiC MOSFETs. The 
experimental test results show that the proposed gate driver can suppress the turn-on overcurrent and turn-off overvoltage of SiC MOSFETs effectively and has little effect on switching loss.

The proposed gate driver can effectively suppress the overvoltage and overcurrent of SiC MOSFETs when compared with the conventional gate drivers. However, it requires five additional digital signals to drive $S_{1}-S_{4}$ and $S_{\mathrm{A} 1}-S_{\mathrm{A} 2}$. In the future, the manufacturer of the gate driver can integrate the proposed gate drive circuit into an integrated gate driver chip to achieve simple control of the proposed gate driver. This is of great significance to promote the wide use of SiC MOSFETs in high-frequency applications.

Author Contributions: J.C. structured the paper, reviewed major references cited and is the main author of the paper. Y.L. contributed to the writing of relevant sections. M.L. provided valuable comments and discussion.

Funding: The authors received financial support from the National Nature Science Fund of China (grant no. 51877007).

Conflicts of Interest: The authors declare no conflict of interest.

\section{References}

1. Wrzecionko, B.; Bortis, D.; Biela, J.; Kolar, J.W. Novel ac-coupled gate driver for ultrafast switching of normally off SIC JFETs. IEEE Trans. Power Electron. 2012, 27, 3452-3463. [CrossRef]

2. Han, D.; Noppakunkajorn, J.; Sarlioglu, B. Analysis of a SiC three-phase voltage source inverter under various current and power factor operations. In Proceedings of the 39th Annual Conference of the IEEE Industrial Electronics Society (IECON 2013), Vienna, Austria, 10-13 November 2013; pp. 447-452.

3. Han, D.; Noppakunkajorn, J.; Sarlioglu, B. Efficiency comparison of SiC and Si-based bidirectional DC-DC converters. In Proceedings of the 2013 IEEE Transportation Electrification Conference and Expo (ITEC), Detroit, MI, USA, 16-19 June 2013; pp. 1-7.

4. Jouha, W.; Oualkadi, A.; Dherbécourt, P.; Joubert, E.; Masmoudi, M. Silicon carbide power MOSFET model: An accurate parameter extraction method based on the levenberg-marquardt algorithm. IEEE Trans. Power Electron. 2018, 33, 9130-9133. [CrossRef]

5. Hashimoto, K.; Okuda, T.; Hikihara, T. A flyback converter with SiC power MOSFET operating at 10 MHz: reducing leakage inductance for improvement of switching behaviors. In Proceedings of the 2018 International Power Electronics Conference (IPEC-Niigata 2018-ECCE Asia), Niigata, Japan, 20-24 May 2018; pp. 3757-3761.

6. Zhang, W.; Xu, X.; Zhang, Z.; Wang, F.; Tolbert, L.M.; Blalock, B.J. Evaluation of 600 V cascode GaN HEMT in device characterization and all-GaN-based LLC resonant converter. In Proceedings of the 2013 IEEE Energy Conversion Congress and Exposition, Denver, CO, USA, 15-19 September 2013; pp. 3571-3578.

7. Kadavelugu, A.; Baek, S.; Dutta, S.; Bhattacharya, S.; Scofield, J. High-frequency design considerations of dual active bridge 1200 V SiC MOSFET DC-DC converter. In Proceedings of the 2011 Twenty-Sixth Annual IEEE Applied Power Electronics Conference and Exposition (APEC), Fort Worth, TX, USA, 6-11 March 2011; pp. 314-320.

8. Wang, Y.; de Haan, S.W.H.; Ferreira, J.A. Potential of improving PWM converter power density with advanced components. In Proceedings of the 2009 13th European Conference on Power Electronics and Applications, Barcelona, Spain, 8-10 September 2009; pp. 1-10.

9. Zhang, W.; Zhang, Z.; Wang, F.; Costinett, D.L.; Tolbert, M.; Blalock, B.J. Characterization and Modeling of a SiC MOSFET's turn-on overvoltage. In Proceedings of the 2018 IEEE Energy Conversion Congress and Exposition (ECCE), Portland, OR, USA, 23-27 September 2018; pp. 7003-7009.

10. Zhang, Z.; Guo, B.; Wang, F.; Tolbert, L.M.; Blalock, B.J.; Liang, Z. Impact of ringing on switching losses of wide band-gap devices in a phase-leg configuration. In Proceedings of the 2014 IEEE Applied Power Electronics Conference and Exposition-APEC 2014, Fort Worth, TX, USA, 16-20 March 2014; pp. 2542-2549.

11. Liu, Q.; Wang, S.; Baisden, A.C.; Wang, F.; Boroyevich, D. EMI suppression in voltage source converters by utilizing dc-link decoupling capacitors. IEEE Trans. Power Electron. 2007, 22, 1417-1428.

12. Lemmon, A.; Mazzola, M.; Gafford, J.; Parker, C. Stability considerations for silicon carbide field-effect transistors. IEEE Trans. Power Electron. 2013, 28, 4453-4459. [CrossRef] 
13. Zhang, Z.; Zhang, W.; Wang, F.; Tolbert, L.M.; Blalock, B.J. Analysis of the switching speed limitation of wide band-gap devices in a phase-leg configuration. In Proceedings of the 2012 IEEE Energy Conversion Congress and Exposition (ECCE), Raleigh, NC, USA, 5-20 September 2012; pp. 3950-3955.

14. Liang, M.; Li, Y.; Chen, Q.; Lu, Y.; Yu, H.; Zheng, T.Q.; Guo, H.; Zhao, F. Research on an improved DC-side snubber for suppressing the turn-off overvoltage and oscillation in high speed SiC MOSFET application. In Proceedings of the 2017 IEEE Energy Conversion Congress and Exposition (ECCE), Cincinnati, OH, USA, 1-5 October 2017; pp. 1358-1365.

15. Yamashita, Y.; Furuta, J.; Inamori, S.; Kobayashi, K. Design of RCD snubber considering wiring inductance for MHz-switching of SiC-MOSFET. In Proceedings of the 2017 IEEE 18th Workshop on Control and Modeling for Power Electronics (COMPEL), Stanford, CA, USA, 9-12 July 2017; pp. 1-6.

16. Li, T.H.; Wang, J.J.; Chung, S.H. An investigation into the effects of the gate drive resistance on the losses of the MOSFET-snubber-diode configuration. In Proceedings of the 2010 IEEE Energy Conversion Congress and Exposition, Atlanta, GA, USA, 12-16 September 2010; pp. 362-369.

17. Pilli, N.K.; Singh, S.K. Influence of peak gate current and rate of rise of gate current on switching behaviour of SiC MOSFET. In Proceedings of the 2017 IEEE Transportation Electrification Conference (ITEC-India), Pune, India, 13-15 December 2017; pp. 1-6.

18. Joko, M.; Goto, A.; Hasegawa, M.; Miyahara, S.; Murakami, H. Snubber circuit to suppress the voltage ringing for SiC device. In Proceedings of the PCIM Europe 2015, Nuremberg, Germany, 19-20 May 2015; pp. 1-6.

19. Camacho, A.P.; Sala, V.; Ghorbani, H.; Martinez, J.L.R. A novel active gate driver for improving SiC MOSFET switching trajectory. IEEE Trans. Power Electron. 2017, 27, 9032-9042. [CrossRef]

20. Dymond, H.C.P.; Liu, D.; Wang, J.; Dalton, J.J.O.; Stark, B.H. Multi-level active gate driver for SiC MOSFETs. In Proceedings of the 2017 IEEE Energy Conversion Congress and Exposition (ECCE), Cincinnati, OH, USA, 1-5 October 2017; pp. 5107-5112.

(C) 2019 by the authors. Licensee MDPI, Basel, Switzerland. This article is an open access article distributed under the terms and conditions of the Creative Commons Attribution (CC BY) license (http://creativecommons.org/licenses/by/4.0/). 